\title{
As Diretrizes Curriculares Nacionais para o Ensino Médio e as proposições sobre trabalho, ciência, tecnologia e cultura
}

reflexões necessárias

MONICA RIBEIRO DA SILVA

Universidade Federal do Paraná,

Curitiba, PR, Brasil

ELOISE MÉDICE COLONTONIO

Fundação da Universidade Federal do Paraná, Curitiba, PR, Brasil

\section{RESUMO}

O estudo analisa os sentidos que adquirem o trabalho, a ciência, a cultura e a tecnologia na sociedade atual e, com base nos referenciais da Teoria Crítica da Sociedade, problematiza a proposição desses elementos nos textos que definem as Diretrizes Curriculares Nacionais para o Ensino Médio (DCNEM). A indagação que motivou esta análise diz respeito à possibilidade de concretização das intenções enunciadas nas diretrizes: de uma educação que visa à produção da autonomia intelectual e moral nos indivíduos. O caminho para a discussão anunciada se fez ao tomar obras de Theodor Adorno, Max Horkheimer e Hebert Marcuse, nas quais se fazem presentes reflexões sobre a tecnologia, a ciência, a cultura e o trabalho e as interfaces possíveis entre esses elementos e os processos formativos. As conclusões sinalizam na direção de que essas propostas não devem ser tomadas de forma instrumental, sob pena de sofrerem um esvaziamento de sentido e, com isso, perderem sua potencialidade.

\section{PALAVRAS-CHAVE}

ensino médio; políticas curriculares; diretrizes curriculares; trabalho, cultura, ciência, tecnologia; Teoria Crítica. 


\title{
THE NATIONAL CURRICULUM GUIDELINES TO THE SECONDARY SCHOOL AND THE PROPOSITIONS ABOUT WORK, SCIENCE, TECHNOLOGY, AND CULTURE: NECESSARY REFLECTIONS
}

\begin{abstract}
The study examines the meanings work, science, culture and technology acquire in today's society and questions, based on the Critical Theory of Society, the proposition of these elements in texts that define the National Curriculum Guidelines for Secondary Education. The question that motivated the analysis concerns the possibility of achieving the intentions set out in the Guidelines, which are those of an education that aims to produce the intellectual and moral autonomy of individuals. The discussion announced was made based on the works of Theodor Adorno, Max Horkheimer and Hebert Marcuse in which reflections on technology, science, culture, and work and the possible interfaces between them and the formative processes are present. The findings indicate the direction that these proposals are not taken in instrumental form, under penalty of becoming empty of meaning and losing, thereby, its potential.

KEYWORDS

secondary education; curricular policies; curriculum guidelines; work; culture; science, technology; Critical Theory.
\end{abstract}

\section{LAS DIRECTRICES CURRICULARES NACIONALES PARA LA ENSEÑANZA MEDIA Y LAS PROPOSICIONES SOBRE TRABAJO, CIENCIA, TECNOLOGIA Y CULTURA: REFLEXIONES NECESARIAS}

\section{RESUMEN}

El estudio analiza los sentidos que adquieren el trabajo, la ciencia, la cultura y la tecnología en la sociedad actual y problematiza, a partir de los referenciales de la Teoría Crítica de la Sociedad, la proposición de esos elementos en los textos que definen Directrices Curriculares Nacionales para la Enseñanza Media. La indagación que motivó el análisis dice respecto a la posibilidad de concreción de las intenciones enunciadas en las directrices, a saber, las de una educación que apunta a la producción de la autonomía intelectual y moral de los individuos. El camino para la discusión anunciada se delineó al tomar obras de Theodor Adorno, Max Horkheimer and Hebert Marcuse en las cuales los autores reflexionan sobre la tecnología, la ciencia, la cultura y el trabajo y las interfaces posibles entre estos y los procesos formativos. Las conclusiones apuntan en la dirección de que esas propuestas no se deben tomar de forma instrumental para evitar que sufran un vaciamiento de sentido y pierdan, así, su potencialidad.

PALABRAS CLAVE

enseñanza media; políticas curriculares; directrices curriculares; trabajo, cultura, ciencia, tecnología; Teoría Crítica. 


\section{INTRODUÇÃO}

Os argumentos presentes na política curricular oficial que estabeleceu novas Diretrizes Curriculares Nacionais para o Ensino Médio (DCNEM), por meio do parecer CNE/CEB n.5/2011 (Brasil,2011) e da resolução CNE/CEB n.2/2012 (Brasil, 2012), apontam para a necessidade de aprofundamento da temática que cerca o eixo ciência, cultura, trabalho e tecnologia, proposto como elemento central da organização pedagógico-curricular da última etapa da educação básica.

Nessa direção, o presente estudo buscou analisar os sentidos que assumem o trabalho, a ciência, a cultura e a tecnologia na sociedade atual e, com base neles, problematizar a proposição desses elementos no interior do texto normativo. A indagação que motivou a análise diz respeito à potencialidade de concretização dos propósitos enunciados nas DCNEM com vistas a realizar um ideal de formação voltado para a consolidação da autonomia intelectual e moral dos sujeitos. A problematização orientou-se em torno da seguinte questão: em que medida tais elementos, por estarem marcados pela racionalidade instrumental orgânica à sociedade atual, não limitariam as intencionalidades de uma educação que visa à emancipação dos indivíduos por meio de sua autonomia intelectual e moral?

O caminho para a discussão anunciada se fez ao tomar obras de Adorno, Horkheimer e Marcuse, nas quais se fazem presentes reflexões sobre a tecnologia, a ciência, a cultura e o trabalho, e as interfaces possíveis entre estes e os processos formativos próprios da sociedade do capitalismo tardio. ${ }^{1}$ Tal referencial se mostrou potencializador da investigação, entre outros aspectos, por estar presente na análise dos filósofos frankfurtianos a crítica rigorosa a esses elementos, tomados como categorias analíticas e explicativas da forma que assume a constituição dos indivíduos em nossa sociedade. ${ }^{2}$ As reflexões presentes em Adorno, Horkheimer e Marcuse possibilitaram

1 A expressão "capitalismo tardio" é utilizada por Adorno com o objetivo de dar destaque para as transformações históricas desde as formulações clássicas de Marx sobre o capitalismo. Tais transformações o levam a concluir que: "Mesmo que se tivesse verificado de modo imanente ao sistema - a lei não inequívoca em Marx - da taxa decrescente de lucro, teria de ser concedido que o capitalismo descobriu em si mesmo recursos que permitem empurrar para as calendas gregas a bancarrota total - recursos entre os quais, inquestionavelmente, estão, em primeiro lugar, a imensa elevação do potencial técnico e, com isso, também a quantidade de bens de consumo que beneficiam todos os membros dos países altamente industrializados. Ao mesmo tempo, em vista de tal desenvolvimento, as relações de produção se revelaram mais elásticas do que Marx imaginara”(Adorno, 1986, p. 63).

2 Julgamos necessário demarcar, de início, a potencialidade das ideias da Teoria da Crítica da sociedade para a análise de questões próprias da atualidade. Nesse sentido, entendemos que hoje nos deparamos com a generalização exponencial da tecnologia, que ocupa todos os espaços de mediação da vida humana; que a ciência multiplica as possibilidades de melhoria das condições da existência e, ao mesmo tempo, nega essas condições para um sem número de seres humanos; que vivemos um contexto em que a experiência formativa propiciada pela mediação da cultura esvai-se na multiplicação imensurável dos bens culturais em sua forma mercadoria; que o trabalho esgota-se no emaranhado campo de diversificação sem precedentes das (im)possibilidades do trabalho e do não trabalho. Diante desses aspectos, reitera-se o caráter profícuo da reflexão do campo frankfurtiano. 
a recuperação do objeto crítico dessas categorias, bem como das relações por elas mediadas entre indivíduo e sociedade.

O texto está estruturado em quatro momentos. No primeiro tecemos considerações que atestam a pertinência do referencial teórico à análise pretendida; em seguida, destacamos dos documentos normativos das DCNEM as proposições em torno do trabalho, da ciência, da tecnologia e da cultura considerados como dimensões da formação humana e base da proposta e desenvolvimento curricular do ensino médio. $\mathrm{Na}$ terceira parte submetemos esses elementos à análise crítica, considerando-os em sua dimensão histórica e problematizando os sentidos que adquirem na sociedade atual. As conclusões a que a análise permitiu chegar encontram-se na quarta e última seção do artigo, que sinaliza para pontos de tensionamento e reflexões necessárias em torno das formas e das limitações históricas do trabalho, da ciência, da tecnologia e da cultura, bem como propõe que sejam elementos em torno dos quais devem se organizar os processos formativos, conforme orienta a política educacional em questão.

\section{ADORNO, MARCUSE, HORKHEIMER E A CRÍTICA AUTOCONSCIENTE A FAVOR DA EMANCIPAÇÃO DOS INDIVÍDUOS}

Horkheimer, na década de 1930, escreveu em seu texto "Teoria Tradicional e Teoria Crítica" (1989) as primeiras concepções sobre a Teoria Crítica da Sociedade. O legado da sociologia alemã e do marxismo de Lukács colaborou substancialmente para a composição intelectual de Horkheimer. ${ }^{3}$

Nesse período Horkheimer rompeu com as formas tradicionais de pesquisa em ciências sociais, e sua discussão central está entre a Teoria Tradicional e a Teoria Crítica: ele pretende desvendar como se dá a relação epistêmica entre objetividade e subjetividade, como o pesquisador/sujeito se porta epistemologicamente diante do seu objeto. As questões que guiam Horkheimer são em síntese: $\mathrm{O}$ que é teoria? $\mathrm{O}$ que é prática? O que é ciência? Para respondê-las, o autor faz o seguinte movimento: afirma o que é "teoria" para depois negá-la, ou seja, Horkheimer contextualiza o que estava sendo considerado como ciência e conhecimento, demonstra o aparecimento de contradições entre as teorias tradicionais (empirismo, positivismo, entre outras) e recusa suas diretrizes. Entretanto, essa recusa não admite de imediato descartar as teorias tradicionais, mas sim, atribuir um sentido a elas: como a ciência e a técnica podem se transformar em mercadoria no modo de produção capitalista.

3 A Teoria Crítica da Sociedade é referência para esta pesquisa por possuir em seu bojo um potencial analítico da realidade atual, e principalmente sobre trabalho, cultura, ciência e tecnologia. Bruno Pucci (2009, p. 164), no artigo "Experiências brasileiras da atualidade da Teoria Crítica" revela mais de quinze grupos de estudos e pesquisas distribuídos no Brasil, entre universidades públicas e privadas, que organizam e produzem temas sobre a relação entre teoria crítica e educação. "A exposição de 'experiências brasileiras' na utilização dos pensadores clássicos frankfurtianos, como referenciais para a pesquisa das questões culturais e educacionais do mundo globalizado, mostra a fecundidade e o potencial investigativo da Teoria Crítica da Sociedade, que se atualiza constantemente na tensão com a realidade econômico-social e se faz cada vez mais presente nas teorias e práxis educacionais". 
$\mathrm{Na}$ Teoria Tradicional, assegura-se o fato e elimina-se o sujeito, utilizando um método generalizado que, em conjunto, soma pressupostos para legitimar sua ciência. A recusa de Horkheimer, assim como a de Adorno e Marcuse, é de fazer ciências sociais com base em métodos homogêneos, que excluem as contradições e os sujeitos, que se regem por dogmatismos comparáveis ao sistema cartesiano.

No início, o desenvolvimento da Teoria Crítica estava mais próximo do terreno marxista, contudo, no mesmo texto de 1937, Horkheimer estabeleceu uma ruptura, em sentido dialético, com o marxismo. Horkheimer nega as teorias tradicionais, abandona alguns aspectos do marxismo e propõe a Teoria Crítica da Sociedade, naquele momento pensada como um materialismo multidisciplinar. Entre as distâncias evidentes em relação às formulações originais do marxismo está a assertiva de que não se depositaria no proletariado a visão privilegiada da sociedade; para esses filósofos da Escola de Frankfurt, essa formulação é tão pragmática e anti-histórica quanto a visão de que nas ciências naturais estariam os fundamentos das ciências sociais. Do ponto de vista da Teoria Crítica, o conceito de classe (e de luta de classes) estaria corrompido pela própria racionalidade tecnológica que se afirma e prolifera no século XX (Matos,1993).

A Teoria Crítica, de acordo com Adorno, Marcuse e Horkheimer, firma seu caráter científico a favor da emancipação humana, especificamente daqueles submetidos à dominação cultural e social. Para produzir ciência e consciência crítica esses pensadores não se valem de juízos de valor, mas sim, do questionamento. A consciência crítica e a ciência são reconhecidas dialética e materialmente na realidade e na história. Afirmar o que é "verdadeiro" ou "falso", "essência" ou "aparência", "ideologia" ou "consciência crítica", depende de uma análise - rigorosa e metodologicamente definida - em que as oposições antagônicas demonstrem seus vínculos de reciprocidade e dependência. Os sentidos de tais oposições são por vezes hostilizados, por vezes fetichizados. A elas se atribuem, historicamente, diferentes significados e, portanto, o problema estaria também em encontrar o "porquê" da hostilização, da fetichização e do privilégio de uma em detrimento de outra, em diferentes contextos. O problema ainda se ramifica em "como" integrá-las e esclarecê-las dialeticamente, para finalmente dar base à consciência verdadeira. Para Pucci (1995, p. 52), ao falar sobre o que é "verdade" na perspectiva da Teoria Crítica, é preciso considerar que:

Cada período histórico desenvolve sua própria verdade, que se transforma no guia de seu processo histórico. Verdadeiro, para os frankfurtianos, é tudo aquilo que promove uma mudança social na direção de uma sociedade racional, ou seja, de uma sociedade que esclareça a luta contra os irracionalismos presentes na barbárie, na violência, na injustiça social, no autoritarismo, no fetiche, no mito etc.

Assim, enquanto as teorias tradicionais em ciências sociais se baseavam em leis absolutas que sustentavam o grau de objetividade e neutralidade para se legitimar, a Teoria Crítica da Sociedade dirige-se para o lado oposto, pois, em sua concepção, a mediação que se interpõe entre objetividade e subjetividade é elemento constitutivo da realidade e da explicação sobre ela. O movimento do pensamento dialético e histórico possui leis não absolutas, isto é, tendências que se negam ou se afirmam conforme as condições históricas objetivas. 
Diante da necessidade e em concordância com Marcuse (1982,p.17), defendemos - na tentativa de recuperar o objeto crítico das categorias ciência, trabalho, cultura e tecnologia na presente análise - que a Teoria Crítica da Sociedade fornece subsídios para situá-los em um ponto de vista histórico e crítico, e com base nessa perspectiva é que nos propomos a submeter à apreciação a legislação que define novas Diretrizes Curriculares Nacionais para o Ensino Médio.

\section{AS DIRETRIZES CURRICULARES NACIONAIS PARA O ENSINO MÉDIO E AS PROPOSIÇÕES SOBRE TRABALHO, CIÊNCIA, TECNOLOGIA E CULTURA}

As justificativas para elaboração de novas diretrizes curriculares para o ensino médio estão anunciadas no parecer CNE/CEB n. 5/2011 e dizem respeito a mudanças recentes na legislação e política educacionais, tais como a criação do Fundo de Manutenção e Desenvolvimento da Educação Básica e de Valorização dos Profissionais da Educação (FUNDEB) e a ampliação da obrigatoriedade da escolarização, resultante da emenda constitucional n. 59, de novembro de 2009. Explicitam-se ainda outros motivos, ancorados nas

novas exigências educacionais decorrentes da aceleração da produção de conhecimentos, da ampliação do acesso às informações, da criação de novos meios de comunicação, das alterações do mundo do trabalho, e das mudanças de interesse dos adolescentes e jovens, sujeitos dessa etapa educacional. (Brasil, 2011, p. 1)

Outra razão apontada e que merece destaque diz respeito ao reconhecimento das necessidades que os jovens têm sinalizado com relação à escola.

O desencaixe entre a escola e os jovens não deve ser visto como decorrente, nem de uma suposta incompetência da instituição, nem de um suposto desinteresse dos estudantes. As análises se tornam produtivas à medida que enfoquem a relação entre os sujeitos e a escola no âmbito de um quadro mais amplo, considerando as transformações sociais em curso. Essas transformações estão produzindo sujeitos com estilos de vida, valores e práticas sociais que os tornam muito distintos das gerações anteriores. Entender tal processo de transformação é relevante para a compreensão das dificuldades hoje constatadas nas relações entre os jovens e a escola. (idem, p. 13)

O parecer toma como referência a relação entre os jovens em sua diversidade as "juventudes" - e a necessidade de atribuição de novos sentidos aos conhecimentos escolares e à própria escola. A relação dos jovens com a escola é considerada basilar para a definição das diretrizes curriculares:

Nos dias atuais, a inquietação das "juventudes" que buscam a escola e o trabalho resulta mais evidente do que no passado. $\mathrm{O}$ aprendizado dos conhecimentos escolares tem significados diferentes conforme a realidade do estudante. Vários movi- 
mentos sinalizam no sentido de que a escola precisa ser repensada para responder aos desafios colocados pelos jovens. (idem, p. 2)

O parecer CNE/CEB n. 5/2011 (Brasil, 2011) parte do reconhecimento de que as novas diretrizes para o ensino médio estão ancoradas na necessidade de conferir outra dinâmica a essa etapa da educação básica e de buscar novas formas de organização do currículo com vistas à ressiginificação dos saberes escolares para que sejam capazes de conferir qualidade e ampliar a permanência dos jovens na escola. Nesse sentido, o texto normativo traz um conjunto de argumentações que buscam qualificar e contextualizar suas proposições: a educação como direito social; o ensino médio com qualidade social; o sentido da escola para as "juventudes"; as especificidades do ensino médio noturno, da educação de jovens e adultos, dos quilombolas, indígenas e do campo, dos estudantes da educação especial estão entre os argumentos que explicam as propostas para a organização curricular segundo essas diretrizes. É elucidativo das intencionalidades dessas diretrizes o trecho seguinte:

A qualidade social da educação brasileira é uma conquista a ser construída coletivamente de forma negociada, pois significa algo que se concretiza a partir da qualidade da relação entre todos os sujeitos que nela atuam direta e indiretamente. Significa compreender que a educação é um processo de produção e socialização da cultura da vida, no qual se constroem, se mantêm e se transformam conhecimentos e valores. Produzir e socializar a cultura inclui garantir a presença dos sujeitos das aprendizagens na escola. Assim, a qualidade social da educação escolar supõe encontrar alternativas políticas, administrativas e pedagógicas que garantam o acesso, a permanência e o sucesso do indivíduo no sistema escolar, não apenas pela redução da evasão, da repetência e da distorção idade/ano/série, mas também pelo aprendizado efetivo. (Brasil, 2011, p. 10, grifos do original)

Entre os pressupostos e fundamentos para um ensino médio considerado de qualidade social e que atenda às finalidades destacadas acima estão o trabalho, a ciência, a tecnologia e a cultura como dimensões da formação humana. Na seção 5.1 desse documento, após essa proposição, são apresentadas as conceituações dessas dimensões:

O trabalho é conceituado, na sua perspectiva ontológica de transformação da natureza, como realização inerente ao ser humano e como mediação no processo de produção da sua existência. Essa dimensão do trabalho é, assim, o ponto de partida para a produção de conhecimentos e de cultura pelos grupos sociais. (idem, p. 19)

Em decorrência dessa compreensão de trabalho, é estabelecida uma concepção de ciência:

A ciência, portanto, que pode ser conceituada como conjunto de conhecimentos sistematizados, produzidos socialmente ao longo da história, na busca da compreensão e transformação da natureza e da sociedade, se expressa na forma de conceitos representativos das relações de forças determinadas e apreendidas da 
realidade. [...] a ciência conforma conceitos e métodos cuja objetividade permite a transmissão para diferentes gerações, ao mesmo tempo em que podem ser questionados e superados historicamente, no movimento permanente de construção de novos conhecimentos. (idem, ibidem)

Entrelaçado aos conceitos de trabalho e de ciência, o texto legal explicita em que termos deve ser entendida a tecnologia como dimensão da formação humana:

A extensão das capacidades humanas, mediante a apropriação de conhecimentos como força produtiva, sintetiza o conceito de tecnologia aqui expresso. Pode ser conceituada como transformação da ciência em força produtiva ou mediação do conhecimento científico e a produção, marcada desde sua origem pelas relações sociais que a levaram a ser produzida. $\mathrm{O}$ desenvolvimento da tecnologia visa à satisfação de necessidades que a humanidade se coloca, o que nos leva a perceber que a tecnologia é uma extensão das capacidades humanas. A partir do nascimento da ciência moderna, pode-se definir a tecnologia, então, como mediação entre conhecimento científico (apreensão e desvelamento do real) e produção (intervenção no real). (idem, p. 20)

Com a mesma finalidade é explicitada a compreensão que se deve ter de cultura:

Entende-se cultura como o resultado do esforço coletivo tendo em vista conservar a vida humana e consolidar uma organização produtiva da sociedade, do qual resulta a produção de expressões materiais, símbolos, representações e significados que correspondem a valores éticos e estéticos que orientam as normas de conduta de uma sociedade. Por essa perspectiva, a cultura deve ser compreendida no seu sentido mais ampliado possível, ou seja, como a articulação entre o conjunto de representações e comportamentos e o processo dinâmico de socialização, constituindo o modo de vida de uma população determinada. (idem, ibidem)

As argumentações formuladas no parecer n. 5/2011 constituem-se em orientações normativas e prescritivas para a oferta e organização curricular do ensino médio presentes na resolução CNE/CEB n. 2/2012 (Brasil, 2012, p. 2):

Art. $5^{\circ} \mathrm{O}$ ensino médio, em todas as suas formas de oferta e organização, baseia-se em:

$[\ldots]$

VIII - integração entre educação e as dimensões do trabalho, da ciência, da tecnologia e da cultura como base da proposta e do desenvolvimento curricular.

As propostas anteriores estão articuladas, nos documentos oficiais, à intencionalidade de uma formação integral que ultrapasse o acesso a conhecimentos científicos e possibilite a reflexão crítica sobre

os padrões culturais que se constituem normas de conduta de um grupo social, assim como a apropriação de referências e tendências que se manifestam em tempos 
e espaços históricos, os quais expressam concepções, problemas, crises e potenciais de uma sociedade, que se vê traduzida e/ou questionada nas suas manifestações. (Brasil, 2011, p. 20)

A capacidade de reflexão crítica seria decorrente, conforme o parecer n. 5/2011, do aprendizado do princípio epistemológico fundamentado na relação entre teoria e prática que permitiria a ação humana de conhecer uma dada realidade e intervir nela. Justamente tendo em vista essa proposta é que se empreendeu a análise em exposição. Se a intenção das diretrizes curriculares para o ensino médio é encaminhar uma organização pedagógico-curricular que conduza os estudantes na direção de uma formação que leve à reflexão e à crítica, e se o caminho para isso seria a articulação dos saberes escolares às dimensões do trabalho, da ciência, da tecnologia e da cultura, consideramos pertinente submeter ao tensionamento crítico essas dimensões e analisar a potencialidade formativa nelas presentes, considerando o caráter histórico das condições em que são produzidas e adquirem objetividade. Esse é o intento deste artigo, que desenvolveremos a seguir.

\section{TRABALHO, CIÊNCIA, TECNOLOGIA E CULTURA PELO CRIVO DA TEORIA CRÍTICA DA SOCIEDADE}

No escopo da Teoria Crítica, a cultura, a ciência, o trabalho e a tecnologia, como todas as relações sociais no capitalismo, foram forjados como objeto. A crítica ao trabalho, nas perspectivas de Marcuse, Adorno e Horkheimer, está contida na análise sobre a cultura. $\mathrm{O}$ trabalho se desenvolve histórica e culturalmente nos diferentes grupos sociais, assim como a técnica, a habilidade, o planejamento e a manipulação da matéria. No contexto do ideário burguês, a exaltação da autonomia individual abstrata e da racionalidade instrumental esteve diretamente articulada à reificação das relações de trabalho.

A formação pelo princípio do trabalho, em que pese a proposição de se orientar para a autonomia, está circunstanciada pela forma que assume o trabalho na sociedade atual, bem como pelos requisitos de formação impostos pelo capitalismo. Adorno (1995) em O que significa elaborar o passado demonstra o quanto a formação dos indivíduos é determinada pelas condições objetivas em que se dá a base material da produção da existência humana. Afirma o autor: "A racionalização progressiva dos procedimentos da produção industrial elimina junto aos outros restos da atividade artesanal também as categorias como a da aprendizagem, ou seja, do tempo da aquisição da experiência no ofício" (idem, p. 33).

No capitalismo, a forma histórica do trabalho articula-se ao uso instrumental da razão, próprio do esclarecimento, e está relacionada ao momento em que a ciência e a tecnologia se convertem em dominação do homem sobre a natureza e sobre os próprios homens. Conforme Adorno e Horkheimer (1985, p. 20-25), o esclarecimento só poderia ser positivo e emancipatório, conquanto assumisse conscientemente a contradição da existência social. Contudo, a consciência esclarecida culmina exatamente com a consciência bárbara, pois sujeitos sem experiência, abstraídos de seu "ser ontológico", 
são desumanos, desprovidos de consciência de si e do outro. O esclarecimento, nesse sentido, causou violência contra a própria natureza humana.

Reconhecer a ciência e tecnologia como meio facilitador do trabalho e da condição humana de existência pode ser uma grande ilusão. Muitos artefatos diminuem a carga de trabalho intelectual e manual, porém essa finalidade não ocorre de forma direta; é sim mediada pelos interesses econômicos e políticos, distintos histórica e geograficamente. Se essa razão fosse direta - quanto mais tecnologia, menos trabalho humano - o tempo de trabalho total seria mínimo e aliviaria a luta pela existência. Para Marcuse (1982, p. 43),

A mecanização cada vez mais completa do trabalho no capitalismo desenvolvido, conquanto mantendo a exploração, modifica a atitude e a condição do explorado. No seio do conjunto tecnológico, o trabalho mecanizado no qual reações automáticas e semiautomáticas preenchem a maior parte (se não o todo) do tempo de trabalho continua sendo, como uma ocupação para toda a vida, uma escravidão exaustiva, entorpecedora, desumana - ainda mais exaustiva por causa do aumento da velocidade do trabalho, controle dos trabalhadores de máquinas (em vez de produto) e isolamento dos trabalhadores uns dos outros. Na verdade, essa forma de servidão é expressiva da automatização coibida, parcial, da coexistência de setores automatizados, semiautomatizados e não automatizados, dentro de uma mesma fábrica, mas, até mesmo sob tais condições a tecnologia substituiu a fadiga muscular pela tensão e (ou) esforço mental.

Marcuse (idem, p. 19) salienta o aspecto de dominação da tecnologia:

Em face das particularidades totalitárias dessa sociedade, a noção tradicional de "neutralidade" da tecnologia não mais pode ser sustentada. A tecnologia não pode, como tal, ser isolada do uso que lhe é dado: a sociedade tecnológica é um sistema de dominação que já opera no conceito e na elaboração das técnicas.

Dessas asserções depreende-se que a racionalidade tecnológica se traduz em racionalidade política e está na base das relações entre indivíduo e sociedade:

Atualmente, esse espaço privado se apresenta invadido e desbastado pela realidade tecnológica. A produção e a distribuição em massa reivindicam o indivíduo inteiro e a psicologia industrial deixou há muito de limitar-se à fábrica. Os múltiplos processos de introjeção parecem ossificados em reações quase mecânicas. O resultado não é o ajustamento, mas a mimese: uma identificação imediata do indivíduo com a sua sociedade e, através dela, com a sociedade em seu todo. (Marcuse, 1982, p. 30-31, grifos do original)

De forma semelhante, Adorno e Horkheimer (1985, p. 144) localizam o indivíduo na sociedade do capitalismo tardio: "Na indústria [no capitalismo tardio] o indivíduo é ilusório não apenas por causa da padronização do modo de produção. Ele só é tolerado na medida em que sua identidade incondicional com o universal está fora de questão". Cabe indagar, portanto, sobre as possibilidades de uma formação 
voltada, por meio do trabalho, para a autonomia do indivíduo no contexto da extrema conversão da tecnologia e da ciência em tecnociência ${ }^{4}$ fundamento da produção na sociedade atual. Essa indagação encontra respaldo, por exemplo, em Marcuse (1982, p. 19), quando ele assevera:

Nessa sociedade o aparato produtivo tende a tornar-se totalitário no quanto determina não apenas as oscilações, habilidades e atitudes socialmente necessárias, mas também as aspirações individuais. Oblitera assim a oposição entre existência privada e pública, entre necessidades individuais e sociais. A tecnologia serve para instituir formas novas, mais eficazes e mais agradáveis de controle e coesão social. [...] A tecnologia não pode, como tal, ser isolada do uso que lhe é dado; a sociedade tecnológica é um sistema de dominação, que já opera no conceito e na elaboração das técnicas.

O "totalitarismo" tecnológico que Marcuse evidencia como sendo a grande tendência da administração por vias da manipulação das necessidades, é o guia das relações de trabalho e da produção da ciência. A máquina é um meio de sujeição do trabalhador à divisão social de trabalho, bem como é instrumento político da razão tecnológica que manipula todos os setores da sociedade, porque "O governo de sociedades industriais desenvolvidas e em fase de desenvolvimento só se pode manter e garantir quando mobiliza, organiza e explora com êxito a produtividade técnica, científica e mecânica à disposição da civilização industrial” (Marcuse, 1982, p. 25-30).

Nos termos da racionalidade tecnológica, a força histórica do proletariado na qual Marx confiava é convertida em energia vital da reprodução do aparato técnico e manutenção da lógica instrumental. No curso da história, Marcuse elucidou alguns aspectos da teoria de Marx que esbarram nas condições em que a ideologia tecnológica se desenvolveu. Obviamente, as condições objetivas da sociedade industrial do século XIX são as responsáveis pelas conclusões a que Marx chegou, e aquelas do século XX foram captadas por Marcuse com o mesmo rigor e excelência.

$\mathrm{O}$ indivíduo alienado do século XX não é mais privado apenas das condições objetivas da sociedade, e sim de sua própria subjetividade. "As forças históricas

4 A conversão da ciência em tecnologia encontra-se contemporaneamente incorporada em processos que demonstram sua intensificação, como, por exemplo, nas experiências em torno da transgenia, da nanotecnologia e da nanociência, já incorporados em produções de larga escala. Como assevera Benthien (2008, p. 117), "O interesse na manipulação e modificação em nanoescala tem relação com a propriedade dos materiais nesta escala, que podem se modificar drasticamente. Tais mudanças consistem, por exemplo, no aumento da reatividade química de alguns elementos, aumento da condutividade elétrica, aumento da resistência do material, mudança na toxidade e na cor. A nanotecnologia é considerada uma tecnologia convergente, na medida em que implica e depende da convergência entre distintas áreas do conhecimento, tais como: informática, neurociências, medicina, química e biologia, podendo ser utilizada e aplicada praticamente em qualquer produto industrial". Em que pese o debate no campo Ciência, Tecnologia e Sociedade (CT\&S) apontar para possíveis implicações éticas e bioéticas, os interesses de mercado cujo potencial se eleva drasticamente têm levado, no entanto, há um descompasso entre a crítica e as precauções do ponto de vista ético e da saúde humana e o emprego dessas tecnologias. 
libertadoras" do proletariado são dissolvidas na homogeneidade entre sujeito, objeto e mercadoria. Aquele cujo esforço físico determinava sua condição de ser trabalhador é, agora, submetido à rotina, ao stress mental e ao ritmo da máquina, fato que dificulta perceber a diferença entre o trabalho produtivo e improdutivo, como Marx qualificava (idem, p. 42-43).

A cultura, nesse sentido, é afirmativa porque, ao pretender conciliar o particular e o universal - e de início é bem-sucedida -, assegurou de forma generalizada a cultura burguesa. A cultura não é um direito, mas um devir. É no plano das ideias que a burguesia arquiteta seu mote de liberdade e igualdade: os indivíduos se tornam iguais na medida em que a cultura universaliza o espírito e são livres enquanto são condicionados pelas relações de troca.

Os antagonismos sociais nos quais a cultura afirmativa obteve seus alicerces não permitiriam a realização dos indivíduos, contudo a hegemonia da cultura afirmativa não estaria segura sem garantir a satisfação do povo, e, para isso, "A felicidade se converte em âmbito privado para poder se manter"(Marcuse, 1998, p. 97). Logo, o indivíduo só é feliz na medida em que possui essa garantia no interior de sua vida privada.

O estranhamento do indivíduo perante o "mundo exterior" - ao objeto e ao seu próprio ser - encerra parte da formação, da consciência e da autonomia, abrindo passagem para a manipulação e para o processo de reificação dos sujeitos. Vale destacar, neste ponto, as palavras de Marcuse (idem, p. 108),

Somente da alma pura pode partir a salvação. Todo o resto é desumano, desprovido de crédito. A alma sozinha evidentemente não tem valor de troca. $\mathrm{O}$ valor da alma não é incorporado nela de modo a se consolidar em seu corpo como objeto que pode se converter em mercadoria. Há uma bela alma num corpo feio, uma alma saudável num corpo doente, uma alma nobre num corpo mesquinho e vice-versa. Existe um cerne de verdade na afirmação segundo a qual o que acontece com o corpo não pode afetar a alma. Mas esta verdade assumiu uma forma terrível na ordem vigente. A liberdade da alma foi utilizada para desculpar a miséria, martírio e servidão. Ela serviu para submeter ideologicamente a existência à economia do capitalismo.

A cultura afirmativa, na medida em que busca sua conservação, se vê diante de obstáculos que ela mesma criou. A exaltação do indivíduo abstrato e da vida privada torna-se insuficiente para a manutenção do controle sobre o processo de produção. A revirada burguesa se deu na reorganização da cultura, na substituição da disciplina individual pela coletiva, no controle parcial pelo controle total do Estado. Para Marcuse (1998, p. 123-124), o indivíduo transitou durante o processo de afirmação da cultura burguesa entre a interioridade idealista e a exterioridade heroica, ambas com a mesma função, porém distintas pelo grau de sacrifício exigido para afirmação da cultura.

Sem intenção imediata de responder "o que é, portanto, a cultura?" ou "que tipo de cultura poderíamos apoiar?”, concordamos com Marcuse, ao dizer que a cultura só cumprirá sua "promessa" quando realizar efetivamente o indivíduo. 
A cultura deve assumir a preocupação com a exigência de felicidade dos indivíduos. Mas os antagonismos sociais que a fundamentam admitem essa exigência na cultura somente enquanto interiorizada e racionalizada. [...] Ela pode se impor unicamente contra a cultura idealista; somente contra essa cultura ela consegue se manifestar como exigência universal. (Marcuse, 1998, p. 100)

Se a cultura, segundo Adorno, Horkheimer e Marcuse, deve se preocupar com a exigência da felicidade dos indivíduos, na atual sociedade regida pela racionalidade instrumental, essa promessa está longe de ser cumprida.

O desafio posto pelos frankfurtianos, portanto, é o de problematizar o conceito de cultura para possibilitar a reflexão sobre outra cultura, aquela que represente os indivíduos e sua relação dialética com a sociedade. A cultura, nesse sentido, define-se ao mesmo tempo como produção material e imaterial da vida. Ao nos depararmos com os insistentes antagonismos entre teoria e prática, trabalho e lazer, e entre as classes sociais, percebemos por fim a Induistria cultural, que atualmente tudo suplanta e deforma. Em síntese, o conceito de cultura,

[...] rejeitou a noção sociológica dominante, segundo a qual a cultura existe de modo autônomo, não relacionada com os processos da vida econômica e política da sociedade. Argumentavam que tal perspectiva neutralizava a cultura e, desse modo, abstraía-a do contexto histórico e social que lhe dava significado. (Giroux, 1983, p. 20)

Para Adorno, toda formação é "formação cultural", sempre um processo de incorporação da cultura pelos indivíduos. A apreensão da cultura ocorre por meio da educação, cujo processo é intencional e com um duplo potencial: adaptar e emancipar os sujeitos. A sociedade transmite conhecimentos aos indivíduos predispondo sua adaptação a um sistema social, e, ao mesmo tempo, esse processo ocorre por inúmeras significações no terreno da subjetividade. São, portanto, dois instantes dialéticos pelos quais produzimos e reproduzimos cultura. Segundo a teoria de Adorno (1996, p. 390-391),

O duplo caráter da cultura nasce do antagonismo social não conciliado que a cultura quer resolver, mas que demanda um poder, que, como simples cultura, não possui. Esse desejado equilíbrio é momentâneo, transitório. Na hipóstase do espírito, mediante a cultura, a reflexão glorifica a separação social colocada entre o trabalho do corpo e o trabalho do espírito. A antiga injustiça quer justificar-se como superioridade objetiva do princípio da dominação, o que apenas demonstra que esta ação sobre os dominados é que mantém e reitera tais relações. Mas a adaptação é, de modo imediato, o esquema da dominação progressiva. $\mathrm{O}$ sujeito só se torna capaz de submeter o existente por algo que se acomode à natureza, que demonstre uma autolimitação frente ao existente.

Nas condições objetivas da sociedade atual, as noções de ciência, cultura e tecnologia estão reféns da razão instrumental, assim como o trabalho. O confronto da razão crítica com a razão instrumental é, portanto, necessário, conquanto seja condição 
imprescindível do desvelamento das formas camufladas e ilusórias que adquirem e medeiam as relações entre indivíduo e sociedade:

A separação entre indivíduo e sociedade, em virtude da qual os indivíduos aceitam como naturais as barreiras que são impostas à sua atividade, é eliminada na teoria crítica, na medida em que ela considera ser o contexto condicionado pela cega atuação conjunta das atividades isoladas, isto é, pela divisão dada do trabalho e pelas diferenças de classe, como uma função que advém da ação humana e que poderia estar possivelmente subordinada à decisão planificada e a objetivos racionais. (Horkheimer, 1989, p. 44)

A formação dos indivíduos pode estar limitada quando nela se apresenta a ausência da crítica à experiência formativa, enquanto mediadora das relações entre indivíduo e sociedade. Com base em Marcuse (1998, p. 166, grifos do original):

Sem essa crítica da experiência o estudante é privado do método e dos instrumentos intelectuais que o habilitam a compreender sua sociedade e a cultura desta como um todo na continuidade histórica, na qual realiza esta sociedade, que desfigura ou nega suas próprias possibilidades e promessas. Ao invés disso, o estudante é mais e mais adestrado para compreender e avaliar relações e possibilidades estabelecidas somente em referência às relações e possibilidades estabelecidas: seus pensamentos, suas ideias, seus objetivos são metódica e cientificamente estreitados - não pela lógica, pela experiência nem pelos fatos, senão por uma lógica depurada, por uma experiência mutilada, por fatos incompletos.

Indivíduos privados de mediações entre a locução e o pensamento são automaticamente assimilados na totalidade racional, tornam-se indivíduos unidimensionais. A responsabilidade da crítica não faz mais sentido, e, mesmo quando faz, trata-se de imitações e reprodução de jargões panfletários.

Para Marcuse, o operacionalismo das ciências físicas estendeu-se a outros campos, inclusive à filosofia. Consiste em um método de empirismo total para "tornar o conceito sinônimo do conjunto de operações correspondente” (Marcuse, 1982, p. 94). O conceito identifica o fato, a linguagem padroniza-o como verdade e, assim, palavra e conceito têm o mesmo conteúdo. O discurso padronizado exclui todo acúmulo de significantes dos conceitos e aborda um único significado, aquele em que plenamente todos devem reproduzir da forma mais previsível possível.

O "fechamento do universo da locução", conforme enunciado por Marcuse, é a privação das mediações necessárias no processo de cognição humana para compreensão e avaliação da realidade. $\mathrm{O}$ fundamento dessa ideia está na racionalização extrema das relações sociais que não permite oposição sobre o formato, os fatos e as "coisas" produzidas por essa sociedade administrada, pois tudo estava a favor do "alto nível de bem-estar” (idem, p. 93). As manifestações do operariado, por exemplo, não erigiam mais sua voz de oposição, as manifestações estudantis eram consideradas irracionais, qualquer postura de contradição tornava-se, aos olhos da administração racional, 
desajustes sociais em relação à imensa camada homogênea e democrática difundida pela linguagem instrumental.

O pensamento unidimensional transforma aquilo que é estranho em familiar por assimilação ou identificação imediata. $O$ diferente é assimilado não como forma de inclusão, mas pela diluição. É preciso, portanto, favorecer o pensamento bidimensional, que segundo Marcuse (idem, p. 103, grifos do original) se encontra na

[...] tensão entre o é e o deve, entre essência e aparência, potencialidade e atualidade - a invasão das determinações negativas e positivas da lógica. Essa tensão constante penetra o universo bidimensional da locução, que é o universo do pensamento crítico e abstrato.

Desse modo, salienta-se a necessidade da reflexão e da crítica sobre os percursos formativos e sobre as bases conceituais e epistemológicas em que tais percursos se movem. A esse percurso, na escola, denominamos currículo. A Teoria Crítica contribui nessa direção ao empreender o resgate das conexões entre sujeito e objeto e ao efetivar a análise profunda das relações sociais e das interfaces entre estas, conhecimento científico e tecnologia. O tensionamento que os autores frankfurtianos fazem sobre a razão instrumental está dialeticamente aliado ao anúncio da razão emancipatória: ao negar o irracionalismo da sociedade tecnocrática, afirma o resgate da emancipação e da crítica.

\section{PARA CONCLUIR: TENSÕES E REFLEXÕES NECESSÁRIAS EM TORNO DAS PROPOSIÇÕES SOBRE TRABALHO, CIÊNCIA, TECNOLOGIA E CULTURA NOS TEXTOS DAS DCNEM}

A discussão traçada na seção anterior permitiu-nos compreender a limitação objetiva das categorias ciência, cultura, trabalho e tecnologia como elementos integradores da formação humana. Esses elementos perpassam por uma crise para além das questões de como conceituá-las ou teorizá-las. A crise da Razão que perdura na sociedade capitalista contemporânea submete a ciência, a tecnologia, a cultura e o trabalho à separação gradativa entre sujeito e objeto, entre ser humano e natureza. Em outras palavras, essas categorias permanecerão desintegradas na realidade concreta enquanto houver a crença exacerbada na razão, a perda de seu sentido desafiador, e enquanto houver esclarecimento que conduza ao conformismo.

As concepções utilizadas nos documentos, analisadas à luz da Teoria Crítica, podem perder seu potencial crítico e emancipador à medida que forem assumidas de maneira instrumental. Ciência e tecnologia, por exemplo, não representam conceitualmente o sucesso da verdade científica a priori sem passarem pelo crivo da crítica filosófica, o que foi possível demonstrar por meio das ideias que Adorno, Marcuse e Horkheimer construíram em suas obras. Cultura e trabalho, igualmente, estão presos à mesma lógica instrumental que anula suas contradições e as submete ao controle da produção e do consumo. Desse modo, torna-se imperativo por parte dos educadores o exercício de uma crítica profunda, com vistas a não tornar tais proposições fragmentos didáticos que apenas conferem aos currículos e às suas práticas a aparência de inovação, 
mas que, na verdade, faz com que eles permaneçam encerrados nos muros intransponíveis decorrentes do fechamento do universo da locução.

Nomear trabalho, cultura, ciência e tecnologia como centro das propostas curriculares para o ensino médio exige mais do que a busca pelos significados de cada um dos elementos que o compõe, e ultrapassa o sentido de justificá-los ou legitimá-los no discurso sobre o currículo. Sinalizamos para o necessário desafio de se buscar, juntamente com os sujeitos jovens e adultos aos quais essas proposições se destinam, os significantes desses conceitos como forma de desvelá-los e explorá-los na história, nas relações de poder e nos interesses que circundam as relações sociais entre o trabalho, a ciência, a tecnologia na contemporaneidade. $O$ texto normativo é expressão de uma prática social, o que torna igualmente relevante a compreensão das relações sociais que tensionam suas proposições, com vistas a superar sua limitação instrumental.

Articulada ao eixo trabalho, ciência, tecnologia e cultura está a afirmação do trabalho como princípio educativo, orientação esta presente nas diretrizes curriculares nacionais para o ensino médio (Brasil, 2011, 2012). Essas orientações se baseiam na perspectiva de se tomar o trabalho como princípio educativo na medida em que os conteúdos e os métodos educativos estejam interessados em reconquistar, ou ainda, reconstruir a ideia de uma classe social excluída da sociedade capitalista pela exploração do trabalho. Nesse sentido, é elucidativa a análise de Horkheimer (1989, p. 37):

Na verdade, a vida da sociedade é um resultado da totalidade do trabalho nos diferentes ramos de profissão, e mesmo que a divisão do trabalho funcione mal sob o modo de produção capitalista, os seus ramos, e dentre eles a ciência, não podem ser vistos como autônomos e independentes. Estes constituem apenas particularizações da maneira como a sociedade se defronta com a natureza e se mantém nas formas dadas. São, portanto, momentos do processo de produção social, mesmo que, propriamente falando, sejam pouco produtivos ou até improdutivos.

Com base nessa referência, é possível compreender que o papel do eixo "trabalho, ciência, tecnologia e cultura" é sua combinação teórica e prática. Trabalho, ciência, tecnologia e cultura combinados estruturam o que o texto das diretrizes para o ensino médio propõe para uma "formação integral do cidadão".

Em outros trechos também se encontra essa combinação intencionada ao exercício da cidadania. O "ser cidadão", nesse sentido, é o que se espera enquanto realização humana, por meio da articulação dos elementos ciência, tecnologia, cultura e trabalho ao processo formativo. Cidadão, nos termos desse documento, seria aquele que por meio da relação entre conhecimentos humanistas e tecnológicos alcançaria "o efetivo exercício da cidadania". Nessa direção, é fundamental diferenciar "formação pelo trabalho" de "formação para o trabalho":

$\mathrm{Na}$ sociedade do capitalismo tardio, a formação tem sido remetida predominantemente à formação para o trabalho, e este, na sua forma mercadoria, circunscreve processos que conduzem a uma semiformação cultural, uma vez que impõe limites à realização da formação de modo a conduzir o homem à autorreflexão crítica, capaz de fazê-lo tomar consciência até mesmo dessa semiformação. Nesse sentido, 
a formação tem destacado privilegiadamente o aspecto da adaptação, e secundarizado o da emancipação. (Silva, 2008, p. 4)

O conhecimento escolar, na forma como se institui e é valorizado na fase do capitalismo tardio, tem - assim como a linguagem, a propaganda etc. - função instrumental. Ciência e tecnologia, por exemplo, no âmbito das experiências curriculares, são tratados, muitas vezes, como conceitos isentos de contradição, assimilados pela falácia de que a ciência é teoria, e a tecnologia, sua aplicação prática. Ou ainda, pela aceitação romântica de que juntas irão proporcionar o progresso social.

Em concordância com Maar (1995), na introdução de Educação e emancipação, quando afirma que "a educação não é necessariamente um fator de emancipação" e que educação, ciência e tecnologia, no contexto contemporâneo, necessitam ser submetidas à crítica permanente, o presente texto teve como intenção valorizar as proposições presentes nas diretrizes para o ensino médio e, ao mesmo tempo, alertar para a necessidade de que essas proposições não sejam fragilizadas pelas incorporações formais, instrumentais, mas que sejam, ao invés disso, submetidas à reflexão rigorosa por parte de todos os que com elas se envolverem.

\section{REFERÊNCIAS}

Adorno, Theodor Ludwig Wiesengrund. Capitalismo tardio ou sociedade industrial. In: Cohn, Gabriel (Org.). Grandes cientistas sociais. São Paulo: Ática, 1986. p. 62-75.

. O que significa elaborar o passado. In: . Educação e emancipação. Tradução de Wolfgang Leo Maar. Rio de Janeiro: Paz e Terra, 1995. p. 388-411.

Teoria da semicultura. Tradução de Newton Ramos-de-Oliveira, Bruno Pucci e Cláudia Barcelos de Moura Abreu. Educação E̋ Sociedade, Campinas: CEDES, ano XVII, n. 56, p. 24-56, dez. 1996.

Adorno, Theodor Ludwig Wiesengrund; Horkheimer, Max. A indústria cultural: o esclarecimento como mistificação das massas. In: . Dialética do esclarecimento. Tradução de Guido Antônio de Almeida. Rio de Janeiro: Zahar, 1985. p. 113-156.

Brasil. Conselho Nacional de Educação. Parecer CNE/CEB n. 5/2011. Diretrizes Curriculares Nacionais para o Ensino Médio. Diário Oficial da União, Poder Executivo, Brasília, DF, 24 jan. 2011. Seção 1, p. 10.

Conselho Nacional de Educação. Resolução CNE/CEB n. 2/2012. Diretrizes Curriculares Nacionais para o Ensino Médio. Diário Oficial da União, Poder Executivo, Brasília, 31 jan. 2012. Seção 1, p. 20.

Benthien, Patrícia Faraco. transgenia e naotecnologia: uma reflexão acerca da relação entre modernidade, novas tecnologias e informação. Theomai, Argentina, n.18, out. 2008. Dispo nível em: <http://revista-theomai.unq.edu.ar/numero18faraco.pdf>. Acesso em: set. 2013. Giroux, Henry. Pedagogia radical. Tradução de Dagmar Zibas. São Paulo: Cortez, 1983. Horkheimer, Max. Teoria Tradicional e Teoria Crítica. In: HorkHEIMER.Tradução de Zeljko Loparic et al. São Paulo: Nova Cultural, 1989. p. 31-68. (Coleção Os pensadores) 
MAAR, Wolfgang Leo. À guisa de introdução: Adorno e a experiência formativa. In: Adorno, Theodor Ludwig Wiesengrund. Educação e emancipação. Rio de Janeiro: Paz e Terra, 1995. p. 11-28.

Marcuse, Herbert. A ideologia da sociedade industrial. O homem unidimensional. Tradução de Giasone Rebuá. Rio de Janeiro: Zahar, 1982.

. Comentários para uma redefinição de cultura. In: . Cultura e sociedade. Tradução de Wolfgang Leo Maar, Isabel Maria Loureiro e Robespierre de Oliveira. Rio de Janeiro: Paz e Terra, 1998. v. II, p. 153-175.

Matos, Olgária Chain Féres. A Escola de Frankfurt. Luzes e sombras do Iluminismo. São Paulo: Moderna, 1993. (Coleção Logos)

Pucci, Bruno. E a razão sefez máquina epermanece entre nós. Piracicaba: Mimeografado, s/d. . (Org.). Teoria Crítica e educação: a questão da formação cultural na Escola de Frankfurt. 2. ed. Petrópolis: Vozes; São Carlos: EDUFISCAR, 1995.

Experiências brasileiras da atualidade da Teoria Crítica. Constelaciones - Revista de Teoria Crítica, Madrid, n. 1, p. 160-164, dez. 2009. Disponível em: <http://campus. usal.es/ revistas_trabajo/index.php/constelaciones/article/viewFile/6647/6639>. Acesso em: 13 abr. 2010.

Silva, Monica Ribeiro da. Currículo e competências: a formação administrada. São Paulo: Cortez, 2008.

\section{SOBRE AS AUTORAS}

Monica Ribeiro da Silva é doutora em educação pela Pontifícia Universidade Católica de São Paulo (PUC-SP). Professora da Universidade Federal do Paraná (UFPR).

E-mail:monicars@ufpr.br

Eloise Médice Colontonio é mestre em educação pela Universidade Federal do Paraná (UFPR). Pesquisadora da Fundação da Universidade Federal do Paraná (FUNPAR).

E-mail: eloise.medice@gmail.com

Recebido em agosto de 2012

Aprovado em setembro de 2013 